\title{
O ensino noturno na Universidade Federal da Bahia: percepções dos estudantes
}

\author{
Jucilene Dias Maranhão a \\ Renata Meira Veras ${ }^{a}$
}

\section{Resumo}

A partir do Programa de Apoio a Planos de Reestruturação e Expansão das Universidades Federais (Reuni), de 2007, a UFBA expandiu de dois para 33 cursos noturnos, chegando a ter mais de 9 mil estudantes neste turno, em 2013. O presente estudo tem o objetivo de conhecer a percepção dos estudantes sobre o Ensino Superior noturno. Entre as bases de estudos que apoiam essa pesquisa estão Arroyo, Furlani e Terribili Filho que discutem, respectivamente, cursos noturnos para trabalhadores oriundos de camadas populares, dificuldades e enfrentamento de propostas pedagógicas, métodos de ensino e políticas públicas. Para tanto, a pesquisa se utiliza da metodologia qualitativa, de abordagem etnometodológica, e se apoia em técnicas de aplicação de questionário, entrevistas individuais e grupos focais. Os resultados da pesquisa apontaram que os estudantes percebem o Ensino Superior noturno da UFBA como fragmentado e incompleto, que, em detrimento da pesquisa e da extensão, o ensino se apresenta neste turno como a única função da universidade. Além disso, os depoimentos constatam problemas estruturais no funcionamento noturno da instituição que comprometem o acesso aos serviços internos que ela oferece. As questões imbricadas nessa pesquisa podem servir de instrumento de reflexão sobre os cursos noturnos numa conjuntura nacional de educação, através da democratização do acesso.

Palavras-chave: Universidade. Ensino Superior noturno. Estudantes. Políticas públicas.

\section{Introdução}

O Ensino Superior noturno tem se apresentado, desde seu surgimento no Brasil, como uma alternativa para estudantes que trabalham (FURLANI, 2001;

a Universidade Federal da Bahia. Salvador, Bahia, Brasil.

Recebido em: 01 dez. 2015

Aprovado em: 28 nov. 2016 
SANTANA, 2013; TERRIBILI FILHO, 2007; VARGAS; PAULA, 2013). Não que se destine exclusivamente para estes, mas as pesquisas apontam que entre os estudantes do noturno de diversas instituições de Ensino Superior, cada vez mais se verifica a relação trabalho e estudo (FURLANI, 2001). Essa associação nem sempre existiu na história do Ensino Superior brasileiro, principalmente no âmbito das universidades federais. As classes trabalhadoras ficaram de fora da educação por muito tempo.

De acordo com Arroyo (2004, p. 83), o campo educativo se configurou de maneira não coincidente com "o caminho seguido pela gente comum", se distanciando dos que trabalham para produzir. Segundo o autor, era normal e contínuo não haver espaço para o trabalho nas carreiras de educação, muito menos para as classes trabalhadoras e produtivas. Almeida Filho et al. (2010, p. 112) corroboram Arroyo (2004) e explicam que a universidade brasileira "[...] sempre foi uma instituição de formação das elites nacionais, os segmentos sociais ascendentes, como regra, encontravam enormes barreiras de acesso à educação superior".

A abertura de cursos superiores noturnos, na segunda metade do século XX, mais precisamente nos anos 1960, proporcionou aos estudantes trabalhadores e trabalhadores estudantes a possibilidade de frequentarem o Ensino Superior. Essa foi uma conquista que se adquiriu de forma gradativa, a partir de pressões populares que exigiam direito à educação. Embora os cursos superiores noturnos datem dos anos 1960, muitas instituições de ensino levaram mais de uma década para se democratizarem, tanto para abertura de cursos quanto para o atendimento às classes trabalhadoras. Somente em 1996, com o advento da Lei no 9.394 (BRASIL, 1996), de Diretrizes e Bases da Educação Nacional, houve a regulamentação da oferta de cursos noturnos nas instituições públicas de Ensino Superior.

Com características diferentes do período diurno, a educação superior noturna se apresenta de uma maneira, ainda hoje, não tão conhecida nas universidades federais brasileiras, haja vista que, ao longo do tempo, sua oferta ficou quase que restrita ao setor privado da educação (TERRIBILI FILHO; NERY, 2009). Há nuances sobre o Ensino Superior noturno e sua população estudantil que se revelam com muita heterogeneidade, entre elas as histórias de vida, as experiências no mundo do trabalho, as relações anteriores ao Ensino Superior travadas com a educação, a situação de classe social, os objetivos para a formação acadêmica e a visão de mundo e de sociedade.

As conquistas adquiridas com as lutas pelo Ensino Superior noturno chegaram à Universidade Federal da Bahia (UFBA) em 1999 e, posteriormente, em 2007, 
quando foram ofertados seus primeiros cursos noturnos ${ }^{1}$. Mas o aumento dessa oferta só se daria, de forma expansiva, em 2009, a partir da adesão ao Programa de Apoio a Planos de Reestruturação e Expansão das Universidades Federais (Reuni). O Reuni é um programa do governo federal, cujo objetivo foi "criar condições para a ampliação do acesso e permanência na educação superior, no nível de graduação, para o aumento da qualidade dos cursos e pelo melhor aproveitamento da estrutura física e de recursos humanos existentes nas universidades federais" (BRASIL, 2007, p. 10).

A partir da adesão ao Reuni, a UFBA deu um salto de 2 para 33 cursos noturnos que funcionam atualmente, enquanto que as matrículas saíram de 336, em 2008, para 2.025, em 2009, chegando a ter, em 2013, um total de 9.141 matrículas $^{2}$ no noturno, correspondendo, aproximadamente, a $26 \%$ de todas as matrículas da instituição (UFBA, 2014a). Apesar de a UFBA já ter sido considerada prestadora de "serviço das elites e instrumento de exclusão social" (ALMEIDA FILHO et al., 2010, p. 295), vem cumprindo com sua responsabilidade social de inserir estudantes de classes populares, conforme mostram as pesquisas (NERY et al., 2011; SANTANA, 2013; UFBA, 2005, 2008). Entretanto, diante desses avanços, é necessário observar se apenas a criação de cursos e a inserção de jovens de classes populares garantem a inclusão social e a permanência bem-sucedida.

A recente expansão de matrículas e de cursos noturnos na UFBA, num contexto em que as demais instituições de Ensino Superior do Estado da Bahia já faziam uma larga oferta neste turno, motivou o surgimento dessa pesquisa. Essa motivação se aliou ao desejo de conhecer a percepção dos estudantes imbuídos nesse processo de expansão, dando aos estudantes trabalhadores e aos trabalhadores estudantes a devida visibilidade e o atendimento adequado.

De acordo com Furlani (2001, p. 11), “[...] tomar a palavra do aluno supõe focalizá-la não como propriedade individual, mas como parte de uma totalidade, mediatizada pelos processos sociais em que se manifesta". Acredita-se que a percepção estudantil pode dar grande colaboração para identificar se os objetivos educacionais da formação universitária estão sendo cumpridos e se precisam ser ajustados, bem como compreender os processos internos de inclusão e exclusão relativos ao Ensino Superior. Além disso, a percepção estudantil pode ajudar na elaboração de ações e políticas da instituição universitária.

\footnotetext{
Em 1999, a Universidade Federal da Bahia aprovou a Resolução n 003/99 que cria os cursos noturnos. O primeiro curso noturno a funcionar na UFBA foi a licenciatura em Física, criado em 1999. O segundo, criado em 2007, se referia à licenciatura em Geografia.

2 Os números de matrícula se referem ao $1^{\circ}$ semestre de cada ano, de acordo com o Relatório de Gestão Simplificado da UFBA (2012) e o Relatório de Gestão Complementar da UFBA (2014B).
} 
Partindo desses pressupostos, este estudo tem como objetivo geral avaliar a percepção dos estudantes dos cursos noturnos da UFBA sobre o Ensino Superior noturno, conhecendo a avaliação que fazem sobre as demais atividades formativas oferecidas pela universidade e identificando os obstáculos que se apresentam durante a formação.

\section{Curso superior noturno: desafios e possibilidades para a formação de estudantes trabalhadores}

Várias pesquisas sobre o Ensino Superior noturno - Cardoso e Sampaio (1994), Furlani (2001), Santana (2013), Terribili Filho (2007), Vargas e Paula (2013) - mostram que o elemento comum entre elas é o fato de a maioria dos pesquisados ser trabalhador, independentemente de exercer uma atividade trabalhista em tempo parcial ou integral.

São muitas as razões pelas quais os estudantes do Ensino Superior noturno trabalham e Arroyo (1990, p. 92) explica algumas delas. Segundo o autor, são estudantes oriundos "[...] de família de renda reduzida, o trabalho é uma exigência para o estudo". Assim, o trabalhador-estudante é "[...] aquele que, iniciado precocemente no trabalho, tenta desde o $1^{\circ}$ grau estudar sem poder deixar de trabalhar para sobreviver e continuar estudando" (ARROYO, 1990, p. 92). Desse modo, o vínculo entre o trabalhador-estudante e o curso noturno representa "[...] a expressão da incapacidade do sistema escolar brasileiro" de equacioná-los devidamente (ARROYO, 1990, p. 93).

Furlani (2001) concorda com Arroyo (2004) ao explicar sobre as desigualdades educacionais no Brasil e as pressões sociais por direito à educação. A autora afirma que até o final dos anos 1960 os estudantes ginasiais, colegiais e universitários pertenciam aos estratos médios e altos da sociedade; já os jovens trabalhadores, os subocupados ou os provisoriamente desocupados pertenciam aos estratos populares e pobres. A maioria dos estudantes do noturno reflete essa situação, pois segundo Furlani (2001, p. 22) "a necessidade de melhorar o orçamento familiar e pressões do consumo, entre outros fatores, impulsionam milhares de crianças e adolescentes dos segmentos inferior e médio a ingressar, precocemente, no mercado de trabalho", postergando o estudo. Somente com a recente democratização do ensino essas pessoas passaram a ter espaço na educação superior, aliando trabalho e educação.

Ainda são muitos os jovens em idade de estudar que trabalham. Segundo o Censo Demográfico de 2010, do Instituto Brasileiro de Geografia e Estatística 
(IBGE, 2010), 14 milhões de jovens de 18 a 24 anos desenvolviam algum tipo de trabalho/ocupação, enquanto apenas 7,3 milhões, com essa mesma faixa etária, frequentavam a escola ou curso superior. De acordo com o IBGE, pessoas com 25 anos de idade, faixa etária suficiente para ter concluído o nível superior, apresentam um nível de instrução bastante comprometido, independentemente de estarem trabalhando: 49,3\% de pessoas sem ocupação não tinham instrução ou tinham apenas o Ensino Fundamental incompleto e $40,8 \%$ de pessoas ocupadas também estavam na mesma situação (IBGE, 2010).

A necessidade de trabalhar se faz muito presente na sociedade, ela é concreta e permeia quase todas as faixas etárias, sobretudo entre as camadas populares, e é lamentável o fato de existirem percentuais tão altos que indicam o baixo nível de instrução dos jovens que deixam de estudar para apenas trabalhar. O trabalho humano foi objeto de análise da obra de Karl Marx e influenciou várias gerações de estudiosos sobre essa questão, sendo base de apoio a movimentos de trabalhadores no mundo inteiro. Para Marx (1996), o trabalho transforma a natureza em materiais que irão preencher as necessidades humanas e vai além de uma determinação genética de relação imediata com o ambiente, como no caso dos animais que o fazem somente para sobreviver:

Antes de tudo, o trabalho é um processo entre o homem e a Natureza, um processo em que o homem, por sua própria ação, media, regula e controla seu metabolismo com a Natureza. Ele mesmo se defronta com a matéria natural como uma força natural. Ele põe em movimento as forças naturais pertencentes a sua corporalidade, braços e pernas, cabeça e mão, a fim de apropriar-se da matéria natural numa forma útil para sua própria vida. Ao atuar, por meio desse movimento, sobre a Natureza externa a ele e ao modificá-la, ele modifica, ao mesmo tempo, sua própria natureza (MARX, 1996, p. 297).

Por ser um processo que tem uma finalidade, mediado pelo homem entre ele e a natureza, o trabalho, como conceito, não é homogêneo, tem suas singularidades inerentes a cada contexto histórico. Nosella (2004) faz uma retrospectiva desse conceito desde a Antiguidade clássica - com os escravos - e Idade Média - com os servos - quando o trabalho era chamado de tripalium, isto é, instrumento de tortura. $\mathrm{O}$ autor discute o conceito burguês de labor, mercadoria que poderia ser vendida livremente nas fábricas e nos serviços modernos, até chegar ao conceito contemporâneo de trabalho como poiesis, ou seja, ação social complexa, política e criativa. Segundo o autor, a poiesis “[...] visa relacionar a máquina com o homem 
universal e eliminar a separação entre trabalhadores das mãos e trabalhadores da inteligência" (NOSELLA, 2004, p. 37).

Essa nova visão do trabalho, que alia os trabalhadores das mãos e trabalhadores da inteligência, ou que extingue essa dicotomia, aliando trabalho e educação em prol do "reino das liberdades", como sugere Nosella (2004), é o que faz muitos estudiosos, legislações e políticas de todo o mundo defenderem que a educação é direito de todos, inclusive para os trabalhadores que ficaram alijados desse processo em muitos momentos da história.

As especificidades do público noturno, sobretudo as do público trabalhador, são quase que negligenciadas nas políticas públicas de educação superior (TERRIBILI FILHO; NERY, 2009; VARGAS; PAULA, 2013). Os indicadores dos órgãos oficiais de educação sempre se apresentam de forma genérica no quesito população estudantil da educação superior, diferenciando-a apenas da educação básica ou técnica. Não apresentam indicadores específicos sobre cada turno do ensino, difundindo-se uma ideia de que o segmento da educação superior é o mesmo para todos os estudantes e fazendo com que as políticas de educação, que surgem com base nessa ideia, considerem a falsa homogeneidade como uma realidade. De acordo com Arroyo (1990), o ensino noturno tem suas especificidades, suas próprias demandas, logo não pode ser analisado e tratado como se fosse idêntico ao ensino diurno. Segundo o autor, os cursos noturnos colocam ao sistema educacional como um todo, e especificamente à universidade, a urgência de rever seus modelos, principalmente a uniformidade entre os cursos.

Furlani (2001) entende que dificuldades pedagógicas apresentadas por estudantes do noturno que trabalham podem ser superadas e, para isso, a instituição de ensino deve retirar "os preconceitos que os cercam", pois "com a ciência e a cultura [os estudantes] crescem, aprendendo a refletir por meio do estudo, da pesquisa" (FURLANI, 2001, p. 165) e da formação universitária com maior qualidade. Para que isso aconteça, a autora afirma que "[...] é preciso modificar propostas pedagógicas que os concebam como carentes, atrasados, incompetentes. É preciso fazer da relação com o conhecimento um desafio, levando-os a recorrer às fontes e à alta cultura e não a apostilas ou à simplificação de conteúdos" (FURLANI, 2001, p. 165).

Terribili Filho e Nery (2009) observam que determinadas questões relacionadas às condições dos estudantes do noturno deveriam ser tratadas por meio de uma política pública de educação, pois tal população estudantil, além de ser um 
grupo frágil e disperso, é bastante numerosa. Além dos obstáculos circundantes da condição de estudante, impostos pela condição de trabalhador, há também problemas relacionados aos métodos de ensino dos professores que desmotivam os estudantes (TERRIBILI FILHO; NERY, 2009). Ter motivação para assistir às aulas expositivas desafia muitos estudantes do noturno, tendo em vista que "o método de aulas expositivas é largamente utilizado", por ser econômico e com ênfase no conteúdo. Além das dificuldades próprias de cada estudante, aquele que "[...] trabalhou durante todo o dia, teve dificuldades com o transporte coletivo, trânsito intenso, mal teve tempo para alimentar-se" (TERRIBILI FILHO; NERY, 2009 , p. 78). Não obstante, ainda terá que enfrentar uma aula cansativa.

Considerando-se a monotonia das aulas expositivas e as dificuldades para motivação dos estudantes, os autores propõem outras didáticas para dinamizar as aulas e estimular a classe:

[...] torna-se necessário que o professor leve ao aluno algo mais desafiador e motivador, com utilização de estratégias e técnicas complementares à aula expositiva, criando um ambiente estimulante, que possibilite a utilização de jogos, dinâmicas e discussões em pequenos grupos, seminários, estudos de caso, simulações, não se esquecendo, porém, das diferenças individuais de cada estudante (TERRIBILI FILHO; NERY, 2009, p. 78).

Para dirimir esses obstáculos que impactam no desempenho e no entorno educacional dos estudantes, os autores defendem que deveriam existir políticas e ações que contemplassem o transporte coletivo para os horários de entrada e saída dos estudantes, haver a gestão do trânsito, facilitando os corredores de acesso às instituições de ensino com grande quantidade de estudantes e melhorar a segurança pública da seguinte maneira:

[...] a segurança pública, com policiamento ostensivo nas proximidades das instituições de ensino, dos locais de estacionamento de veículos e nos bairros, com policiais distribuídos próximos a estações do metrô e paradas de ônibus, sobretudo no horário das $22 \mathrm{~h} 00$ à meia-noite, que é o horário de pico de movimentação dos estudantes entre as instituições de ensino e suas residências (TERRIBILI FILHO; QUAGLIO, 2005, p. 85).

Para Barreiro e Terribili Filho (2007), se não houver a criação de políticas públicas, com urgência, corre-se o risco de os estudantes do noturno virarem "mais 
uma categoria de excluídos" (p. 96) formada por aqueles que não conseguem concluí-lo ou que o concluem com defasagens para enfrentar o mundo do trabalho. É exatamente sobre essa questão que Arroyo (1990) se refere, quando sustenta que a instituição que se propõe a ter curso noturno precisa pensar na viabilidade administrativa, de maneira que a estrutura dos institutos noturnos ofereça as condições necessárias para a aproximação entre o trabalhador e as possibilidades de conhecimento que a universidade pode oferecer, como um currículo adequado, com aproximação e enriquecimento de formação e trabalho, teoria e prática, reflexão e produção.

Quando existe uma gestão administrativa de programas de assistência estudantil, no sentido de atender às necessidades materiais e pedagógicas dos estudantes, bem como de uma gestão das condições físicas dos espaços e serviços da instituição, no período noturno, já há um bom caminho andado para uma permanência mais bem-sucedida entre esses estudantes.

O Ensino Superior brasileiro carrega consigo grandes preocupações sobre como está sendo realizado e sobre os efeitos que pode causar na formação do estudante. Quando é tratado por turno de funcionamento, como é o caso do turno noturno, carece ainda mais de uma análise mais detalhada, dadas as especificidades que este turno possui. A atenção especial que o período noturno merece se deve pelo fato de ter se difundido mais tardiamente que o período diurno e os direitos educacionais encontraram ainda mais entraves para se concretizar. Arroyo (1990) discute a situação dos cursos noturnos e dos estudantes trabalhadores que os frequentam e indaga qual a função social do Estado e da universidade para as classes trabalhadoras que adentraram o Ensino Superior.

Luckesi et al. (1991), por sua vez, afirmam que a educação superior brasileira ainda tem apresentado restrições, sobretudo no que se refere à repetição e difusão do saber elaborado em outras realidades, em detrimento da realização de investigações que poderiam partir das necessidades locais. Nesse sentido, os autores manifestam que não se pode aceitar que a instituição de Ensino Superior seja “[...] uma universidade escola, em que se faça tão somente ensino, onde não exista efetivamente campo, abertura e infraestrutura que permitam e incentivem a pesquisa. Uma universidade sem pesquisa não deve, rigorosamente, ser chamada de universidade" (LUCKESI et al., 1991, p. 39).

No entendimento do Fórum de Pró-Reitores de Extensão das Universidades Públicas Brasileiras (Forproex), o Ensino Superior promovido pelas universidades precisa conceber seu currículo da seguinte maneira: 
[...] um novo paradigma curricular no qual é inevitável a indissociabilidade ensino-pesquisa-extensão enquanto eixo de formação do estudante, de uma perspectiva na qual a graduação vai além da mera transmissão para se transformar em espaço de construção do conhecimento, em que o estudante passa a ser sujeito, crítico e participativo, para o qual a flexibilização aparece como um meio de viabilização (FORPROEX, 2006, p. 44).

Percebe-se, a partir da ideia do Forproex, que a formação proporcionada pela graduação deve ir além de ensino e pesquisa e contemplar a extensão universitária, de maneira que os três sejam indissociáveis. Assim, a formação do estudante, advinda de um currículo que preze o ensino, a pesquisa e a extensão e que valorize a construção do conhecimento, pode tornar o estudante em sujeito mais atuante, mais crítico e participativo. Nesse particular, Paulo Freire (1983) argumenta que, nas relações travadas no contexto da educação, todos os atores, educandos e educadores, são sujeitos críticos e pensantes e que a extensão deve ser entendida como um processo de comunicação, de diálogo que venha respaldar essa atuação crítica. Para o autor, quando ocorre a comunicação, a relação dialógica no processo educativo, o estudante passa a pensar criticamente.

Na UFBA, o Estatuto e Regimento Geral apresentam um novo marco normativo para o papel social da universidade visto como conjunto articulado de funções sociais. Essas funções são o ensino - práxis de formação de sujeitos epistêmicos; a pesquisa como produção intelectual e cultural aberta à epistemo-diversidade da cena intelectual contemporânea; e a extensão -, é a práxis educacional, num mundo cada vez mais multirreferenciado e intercultural. Com essas funções, a universidade poderá realizar a produção formativa, intelectual ou acadêmica e a produção política (UFBA, 2010).

\section{Abordagem metodológica}

As situações cotidianas da vida estudantil oferecem valiosas informações para a instituição de ensino e os pesquisadores sociais. Partindo desse pressuposto, a pesquisa qualitativa foi escolhida para investigar as percepções dos estudantes do Ensino Superior noturno sobre a formação na universidade e as implicações que esta acarreta junto à condição social do estudante. A metodologia qualitativa permite "conhecer as razões e os motivos que dão sentido às aspirações, às crenças, aos valores e às atitudes dos homens em suas interações sociais" (FRASER; GONDIM, 2004, p. 151). 
De acordo com Bauer e Aarts (2002, p. 21), a pesquisa qualitativa é oriunda da pesquisa social: "na pesquisa social, estamos interessados na maneira como as pessoas espontaneamente se expressam e falam sobre o que é importante para elas e como elas pensam sobre suas ações e a dos outros". Os autores afirmam que o principal objetivo da pesquisa social é a categorização do problema, ou seja, categorizar o presente ou categorizar as pessoas de acordo o que elas leem, olham, escutam.

Nesse sentido, o foco direcionou-se para a compreensão da realidade particular dos estudantes do período noturno na sua complexidade, dentro da macrorrealidade da educação superior. Considerando-se esse enfoque de pesquisa, a opção metodológica para o constructo de análise baseou-se na etnometodologia. Oriunda dos estudos sociológicos de Garfinkel (2009), a etnometodologia teve significativa importância para pesquisas que investigam o que os sujeitos percebem, descrevem e propõem em situações cotidianas que envolvem grupos e relações. Entre as correntes teóricas que influenciaram Garfinkel, há a teoria da ação de Parsons, a fenomenologia social e o interacionismo simbólico. Para Garfinkel (2009, p. 119), a etnometodologia se refere "[...] à investigação das propriedades racionais de expressões indexicais e outras ações práticas como realizações contínua e contingentes de práticas engenhosas da vida cotidiana".

Preocupados com os problemas sociais, entre eles os problemas da área da educação, os estudos da etnometodologia também influenciaram muitos teóricos, como o sociólogo Coulon, que se dedicou à pesquisa sobre a vida universitária de estudantes franceses. O autor (1995) elenca cinco conceitos da etnometodologia que permitem compreender os elementos fornecidos em pesquisas sociais: a prática/realização, a indicialidade/indexalidade, a reflexividade, a accountability e a noção de membro. O primeiro conceito (prática/realização) explica que as práticas dos atores sociais, como as crenças e os comportamentos, constituem as ações socialmente organizadas e pressupõe que "[...] a realidade social é constantemente criada pelos atores, não é um dado preexistente" (COULON, 1995, p. 31). O segundo conceito (indicialidade/indexalidade) se refere à fala, ao enunciado, à linguagem como um indicador de um contexto e que este contexto deve ser levado em consideração no significado da linguagem. Para Coulon (1995, p. 33), as "[...] palavras só ganham seu sentido 'completo' no seu contexto de produção, quando são 'indexadas' a uma situação de intercâmbio linguístico". $\mathrm{O}$ terceiro conceito (reflexividade) não se refere à reflexão, pois, conforme explica (1995, p. 42), reflexão e reflexividade não podem ser confundidas. Verifica-se que quando os atores sociais descrevem uma situação, estão também a constituindo: "a reflexividade designa a equivalência entre descrever e produzir uma interação, entre a compreensão e a expressão dessa compreensão", ou seja, ela designa 
as práticas que "descrevem e constituem o quadro social" ao mesmo tempo. $\mathrm{O}$ quarto conceito (accountability) diz respeito às descrições que constituem o mundo social, mais precisamente a uma descritibilidade dos atores. Segundo Coulon (1995, p. 45), "dizer que o mundo social é accountable significa que ele é algo disponível, isto é, descritível, inteligível, relatável, analisável. Essa analisabilidade do mundo social, a sua descritibilidade e sua objetividade se mostram nas ações práticas dos atores". O quinto e último conceito (noção de membro) trata do membro como aquele que domina a linguagem comum do seu grupo social e que é dotado de métodos e modos de agir que lhe permitem adaptar-se ao contexto em que vive:

Tornar-se um membro significa filiar-se a um grupo, a uma instituição, o que exige o progressivo domínio da linguagem institucional comum. Essa filiação repousa sobre a particularidade de cada um, sua maneira singular de enfrentar o mundo, de 'estar-no-mundo' nas instituições sociais da vida cotidiana (COULON, 1995, p. 48).

Partindo desses conceitos etnometodológicos, pode-se inferir que a percepção do estudante do noturno, apresentada por meio de suas descrições, relatos e análises, pode ajudar a compreender várias questões implicadas com o Ensino Superior, principalmente com a instituição universitária, podendo revelar alternativas de mudanças para o contexto atual. O estudante, enquanto um membro de um grupo micro e macro social que é a instituição de ensino, percebe e constrói a universidade por um viés que pode ser desvelado através de uma pesquisa qualitativa amparada na etnometodologia.

Conhecer esses atores do Ensino Superior noturno, suas vivências e percepções sobre os cursos da UFBA, através da imersão em campo, foi o fator preponderante para desenvolver essa pesquisa. Após a definição do objeto de estudo e da revisão da literatura a respeito do tema, iniciou-se a seleção dos participantes da pesquisa.

Inicialmente, foi feita uma observação dos cursos noturnos existentes na UFBA para definir quais deles poderiam ser usados na pesquisa. Dos 33 cursos noturnos funcionando na universidade, 31 estão lotados no campus Salvador. Desses, há 19 que possuem algum tipo de equivalência com os cursos diurnos e/ou são totalmente compatíveis em sua natureza interdisciplinar ou linear. Estes cursos permitem ao candidato, que se inscreve no processo seletivo, escolher pelo diurno ou noturno, sem que haja grandes diferenças na modalidade de curso. Destarte, optou-se por pesquisar estudantes desses 19 cursos para conhecer os motivos dessa escolha. Os cursos elegidos foram as licenciaturas em Física, 
Geografia, Matemática, Química, Ciências Biológicas, História, Pedagogia, Letras Vernáculas, Língua Estrangeira Inglês/Espanhol e Dança; os bacharelados tradicionais Arquitetura e Urbanismo, Farmácia, Arquivologia, Direito e Ciências Contábeis; e os bacharelados interdisciplinares em Humanidades, Ciência e Tecnologia, Artes e Saúde.

Os bacharelados tradicionais e interdisciplinares são totalmente equivalentes, compatíveis aos cursos diurnos de mesmo nome. Já as licenciaturas em Dança e Pedagogia funcionam como bacharelados no diurno e como licenciaturas no noturno. As demais licenciaturas funcionam no diurno como bacharelados e licenciaturas, enquanto que no noturno são apenas licenciaturas.

Posteriormente, delimitou-se os critérios de inclusão dos sujeitos da pesquisa - ser estudante do noturno de um dos 19 cursos definidos previamente e desenvolver alguma atividade remunerada, de modo que empreendesse sua capacidade laboral.

A abordagem dos estudantes participantes seguiu os dois critérios básicos de seleção, sendo realizada no segundo semestre de 2014, nos horários de chegada, intervalos e saída das aulas. Considerou-se o contexto social; alguns estudantes participaram em horários de aulas vagos e com outros, cujo professor julgou relevante a participação na pesquisa, realizou-se um grupo focal no horário de aula.

Os instrumentos para a coleta de informações foram: questionário, entrevistas individuais semiestruturadas e grupo focal. A pesquisa foi realizada em duas fases e na unidade de ensino de cada estudante. A primeira fase consistiu de entrevistas individuais e a segunda dos grupos focais. Ao todo, participaram 39 estudantes, sendo que 20 integraram a primeira fase e 19 a segunda fase. Os participantes dos grupos focais não foram os mesmos da entrevista individual e vice-versa.

Das entrevistas individuais, participaram estudantes dos 19 cursos delimitados. Já os grupos focais foram organizados com estudantes de três cursos: Pedagogia, com quatro participantes, Direito, com seis participantes, e Bacharelado Interdisciplinar em Humanidades com nove participantes. As entrevistas foram gravadas e transcritas e a identidade dos entrevistados foi mantida em sigilo sendo utilizados nomes fictícios.

As entrevistas aconteceram presencialmente, por entender que seus atores, estudantes e pesquisadora, teriam mais chance de conversar sobre as vivências e as percepções da vida universitária. Esse tipo de entrevista é interessante porque "[...] fornece os dados básicos para o desenvolvimento e a compreensão das relações 
entre os atores sociais e sua situação", além de "[...] mapear e compreender o mundo da vida dos respondentes e o ponto de entrada para o cientista social que introduz, então, esquemas interpretativos para compreender as narrativas dos atores em termos mais conceptuais e abstratos" (GASKELL, 2002, p. 65).

Devido às vantagens e limitações de cada tipo de entrevista, percebeu-se a necessidade de se fazer um enfoque multimétodo, ou seja, a integração dos resultados das entrevistas individuais e dos grupos focais, bem como os dados de identificação do questionário (GASKEL, 2002; GONDIM, 2003). Dessa forma, as limitações da entrevista individual puderam ser mais exploradas nos grupos focais, além de explorar também os consensos e as divergências, sobretudo as preocupações comuns ao grupo.

Nas entrevistas individuais investigou-se mais em profundidade a percepção individual sobre os aspectos delimitados na pesquisa. Já os grupos focais tiveram um direcionamento maior para a percepção sobre as metodologias de ensino no curso noturno e os fatores externos ou internos que influenciam o desempenho nos estudos, pois "a situação grupal, a partilha e o contraste de experiências constrói um quadro de interesses e preocupações comuns que, em parte experienciadas por todos, são raramente articuladas por um único indivíduo" (GASKELL, 2002, p. 77).

Os textos transcritos das entrevistas formaram um corpus, isto é, um material com funções simbólicas (BAUER; AARTS, 2002). O tamanho do corpus é restrito e intencional, respeita o tempo da pesquisa para que as informações coletadas não virem "[...] porões de dados: materiais coletados, mas nunca de fato analisados" (BAUER; AARTS, 2002, p. 60). A construção do corpus leva em consideração as diversas nuances dos pesquisados e, nesse sentido, as percepções particulares apresentadas na pesquisa fazem uma tipificação de representações ainda pouco conhecidas acerca de estudantes do noturno da UFBA.

Há uma variedade de análises dos discursos, oriundas das diversas tradições teóricas, porém a tradição etnometodológica dialoga com a análise do corpus, do material coletado nesta pesquisa. A etnometodologia se interessa não só pelas narrações, mas principalmente pelo que elas têm como objetivo, a partir das interações sociais (GIL, 2002). Os etnométodos dão relevância ao caráter indexical do discurso na análise dos relatos pesquisados. Gil (2002, p. 244) afirma que os muitos estilos de análises do discurso existentes têm em comum "a rejeição da noção realista de que a linguagem é simplesmente um meio neutro de refletir, ou descrever o mundo, e uma convicção da importância central do discurso na 
construção da vida social". Essa convicção é partilhada pela etnometodologia, quando enfatiza a investigação da analisabilidade e a descritibilidade das ações sociais.

Portanto, a análise dos resultados dessa pesquisa foi feita com base nos conceitos da etnometodologia já apresentados, dada a sua proximidade com os achados na investigação. Os resultados foram organizados em duas categorias: "A formação universitária: ensino, pesquisa, extensão e participação discente" e "O funcionamento dos espaços da universidade no período noturno".

\section{Percepções estudantis: a formação universitária e o funcionamento noturno da UFBA}

Os resultados apontados nessa pesquisa indicam duas vertentes que serão discutidas separadamente: formação universitária e o funcionamento do noturno da UFBA.

\subsection{A formação universitária: ensino, pesquisa, extensão}

Essa categoria traz uma riqueza de informações que agrega muitos detalhes sobre a percepção dos estudantes acerca da formação na universidade. Para organizar melhor essas informações, será abordado primeiro o que eles pensam sobre o ensino, depois sobre a pesquisa e a extensão.

\subsubsection{Ensino dos professores}

Nessa subcategoria, a maioria dos estudantes considerou aspectos positivos e negativos, bem como metodologias satisfatórias e não satisfatórias dos professores para o seu aprendizado. Dessa forma, os itens mais abordados pelos entrevistados foram: ensino tradicional e ensino dinâmico, aulas didáticas, e aulas conteudistas e cansativas.

Há estudantes que sintetizam muito bem as características de um ensino tradicional e de um ensino mais dinâmico ou renovado existentes num mesmo curso e citam a metodologia da pedagogia de Paulo Freire. Conforme os entrevistados, essas diferentes formas de ensinar repercutem de maneira distinta em sua percepção e em sua participação nas aulas:

O que eu posso ver, infelizmente, é que a universidade pública ainda tem um tradicionalismo muito grande. Nós temos professores ainda com a formação muito... aquela coisa assim que o professor fala, o aluno recebe e não questiona. Infelizmente a formação não é 
muito didática, é claro que com suas exceções. Mas, grande parte das disciplinas foram aquelas de carteiras montadas em fila, de prova, só leitura, leitura, leitura, o professor fala, o aluno recebe e o aluno não tem a possibilidade de questionar, de transformar. Por outro lado, tive também algumas experiências com os professores de base bastante freiriana, com a metodologia lúdica e diversificada que é o que muitas vezes motiva o aluno a participar da aula. Com essas experiências de professores mais tradicionais muitas vezes eu não me senti à vontade de debater, de questionar. O que é contrário quando você encontra um professor que lhe dá essa abertura, de trabalhar uma aula de maneira mais dinâmica, mais aberta (Cláudia, estudante de Bacharelado Interdisciplinar em Humanidades).

Os estudantes consideram como ensino tradicional aquele em que o professor é detentor do saber e depositário do conhecimento, que organiza a aula de maneira em que o estudante não tem muitas possibilidades de se expressar, como da estruturação do espaço da sala de aula com cadeiras enfileiradas, aulas expositivas e ênfase na leitura e prova. Essa percepção se apoia no que Soares (2009) chama de modelos pedagógicos tradicionais, caracterizados pela transmissão de saber em aulas magistrais. A autora esclarece que o modelo pedagógico tradicional é intelectualista e se traduz pelas formas de controle e de avaliação. Freire (2007), citado pela estudante, rebate o ensino tradicional com transmissão do conhecimento, porque esse ensino não leva à consciência crítica do estudante. Freire (2008) qualifica essa forma de ensinar como educação bancária, comparando o professor como depósito de conhecimento e o estudante como depositário.

Por outro lado, os estudantes se referem a professores que desenvolvem um ensino lúdico, dinâmico, diversificado e motivador, no qual sentem mais liberdade para participar, debater e questionar. Não generalizam o ensino dos professores como sendo tradicional ou dinâmico, mas indicam que no mesmo curso eles têm ensinos distintos, porém atribuem para cada um os adjetivos ruim e bom, respectivamente. Esse ensino que dá mais liberdade para participação estudantil caminha para a perspectiva trazida pelo Forproex (2006) sobre a graduação como um espaço de construção do conhecimento, no qual o estudante atua como sujeito crítico e participativo, não apenas como mero receptor de conhecimento.

[...] eu posso dizer que sou até um privilegiado em relação aos colegas, que eu não tive problema, assim, nenhum, com professor [...]. Eu posso contar que no semestre passado eu tive uma disciplina $[\ldots]$ e nós tivemos uma experiência muito 
positiva. E, justamente, um dos temas dessa disciplina, que foi em Contemporaneidade I, foi o acolhimento na universidade. Esse professor foi muito importante até pra nossa permanência na universidade porque foi um momento difícil [...]. Ele segurou muito a onda do grupo e foi tão importante que até hoje as pessoas que fizeram parte dessa turma nós nos falamos, nos cumprimentamos. Tinha uma coisa que ele fazia, desde a primeira vez, um "abraçaço", eu nunca fiz aquilo numa sala de aula. E o professor perguntava: - Como é que nós vamos sair daqui? Era assim, era a "Sexta da Amizade". Então, pra mim, foi uma coisa que marcou o início do meu curso aqui e que me fez permanecer aqui (Jean Carlos, estudante de Bacharelado Interdisciplinar em Humanidades).

Sobre um ensino mais didático, os estudantes percebem e indicam como ele acontece, principalmente quando se diversifica com aulas externas ao espaço da sala de aula. Comparam este ensino com o de outros professores que não contemplam adequadamente seus interesses de aprendizagem no curso.

Em geral, o ensino dos professores é bom, porém existem algumas dificuldades, alguns professores abordam o assunto de forma diferente, têm um tratamento diferente com os alunos. O comportamento de alguns, eu acho que não é adequado para o ambiente de ensino. Tirando isso, em geral, acho legal a forma como eles ensinam, são bem didáticos. A gente tem aula fora da faculdade, apesar de ser um curso noturno sempre tem aula aos sábados fora da faculdade, visitas técnicas... (Rodrigo, estudante de Arquitetura e Urbanismo).

Tem muitos professores bons, mas alguns têm uma visão mais voltada para o ensino e outros com visão voltada para pesquisa. Quero dizer o seguinte, que alguns professores se preocupam em ensinar, em passar o assunto tranquilamente, outros não, passam de forma bem rígida mesmo, como se a gente fosse pesquisador (César, estudante de Física).

A fala do estudante de Física remonta à questão referente às duas primeiras missões da universidade, o ensino e a pesquisa, que sempre tiveram problema para se associar. A formação universitária fragmentada, em decorrência dessa dissociação, é explicada por Soares (2009) quando afirma que, desde a formação de professores na pós-graduação, a pesquisa é muito mais incentivada e valorizada 
do que o ensino e a intervenção educativa. Paivandi (2013) reforça que "articular pesquisa e ensino permanece uma questão espinhosa no mundo universitário". Dessa forma, o estudante sente o impacto daquele ensino que se volta para a pesquisa sem a intervenção educativa, considerando-o muito rígido. A ideia proposta por Libâneo (2009) de se fazer um ensino com pesquisa, que perpasse o ensino e vice-versa, pode ajudar a dirimir essa fragmentação tornando-se uma excelente estratégia de formação para as capacidades mentais dos estudantes.

Os participantes da pesquisa também reconhecem que o ensino engessado e conteudista de muitos professores pode ser fruto de um ensino tradicional que tiveram ao longo de sua formação, logo não conseguem se libertar e o reproduzem em sala de aula. Paralelamente a isso, há práticas de ensino em que se estimula a autonomia, a análise crítica da realidade, a problematização ou construção de soluções para os problemas sociais:

Eu vejo a maioria dos professores, em si, reproduzindo o modelo tradicional de ensino, aquele modelo conteudista, onde o aluno é depositário do conhecimento. Eu não imaginava que eu ia encontrar dentro do Bacharelado Interdisciplinar aqui, professor chegar numa sala de aula e começar a ministrar uma aula expositiva, meramente expositiva, que chega a ficar fazendo leitura de slides e ao término da leitura pergunta ao aluno: - Entendeu? Alguma dúvida? Eu não consigo pensar, na perspectiva de processo de formação que o Bacharelado Interdisciplinar, em si, criou, que pelo menos traz dentro de sua proposta, de seu projeto original, ter professores com essa perspectiva. E eu consigo analisar ou, pelo menos, seria uma explicação para isso, é que esses professores, eles vêm da perspectiva acadêmica tradicional. Então, se são produtos dele, a tendência é reproduzir. Isso é um fato! [...] mas, eu consigo ver, em raríssimas exceções, um professor ou outro que consegue, de fato, praticar a aula dentro daquela perspectiva, procurando desenvolver nos alunos aquelas situações de autonomia, de perspectiva de análise crítica da realidade, de propor certas soluções ou problematizar soluções, de tentar construir uma solução dentro dessa perspectiva em sala de aula, mas a maioria eu não consigo ver isso (Mário, estudante de Bacharelado Interdisciplinar em Saúde).

Nesse sentido, há estudantes que informam que mesmo em curso de licenciaturas, voltados para formar professores, as práticas docentes também são cansativas e monótonas, carregadas de tradicionalismos, sobretudo para estudantes do 
noturno que estão cansados da jornada de trabalho praticada durante o dia. Argumentam que há uma contradição, porque se exige dos discentes que aprendam novas metodologias para utilizar na sua vida profissional, mas seus formadores utilizam metodologias antigas nas aulas da graduação. Por outro lado, os entrevistados informam que há docentes que conseguem realizar aulas dinâmicas e atrativas:

$\mathrm{Na}$ verdade, a questão da metodologia não é nem diferente no noturno, eles dizem que há uma diferença, porque o pessoal do noturno trabalha, mas na verdade não é porque eu já fiz disciplina de manhã também e eu percebi que a dinâmica é a mesma, a didática é a mesma. O que eu acho complicado, principalmente, pra Pedagogia é que eles têm uma metodologia para com a gente sempre tradicional, tradicionalista e querem que a gente aplique uma metodologia diferente com os alunos. Então, isso entra em choque. Eles têm uma metodologia tradicional, não que seja ruim, mas a gente precisa aplicar uma nova metodologia com os alunos. Então, fica uma interrogação: Como fazer isso, como melhorar se nós estamos em uma faculdade que a todo tempo nós precisamos de uma dinâmica diferente e nós não encontramos aqui? É claro que pra metodologia do noturno o ideal é que o professor venha com uma metodologia bem mais dinâmica, porque os alunos já vêm cansados, então, precisa que eles fiquem acordados e não ficar com as metodologias maçantes: texto, texto, texto, texto... A leitura é essencial, claro que é. O aluno deve ler? Deve. Mas, na sala de aula aproveitar esse momento que o aluno já deve ter reservado um tempo pra ler o texto e dinamizar a leitura. Alguns professores, claro, fazem isso muito bem, outros nem tanto (Marco Antônio, estudante de Pedagogia).

Terribili Filho e Nery (2009) propõem didáticas mais desafiadoras e motivadoras que poderiam dirimir as dificuldades dos estudantes com relação às aulas tradicionais. Nessa proposta, a didática dos professores pode utilizar técnicas, como jogos, dinâmicas, discussões em pequenos grupos, seminários, estudos de caso, simulações, que complementem as aulas. Tal proposta poderia estimular os estudantes e, quiçá, ajudar a desfazer a imagem negativa dessas aulas, já que não são tomadas como referência para aplicar futuramente na vida profissional, na qual, também, atuarão como professores.

Apesar de terem sido poucas as avaliações que analisam positivamente o ensino dos professores, o registro deles é de grande relevância, porque mostra ser 
possível desenvolver um trabalho pedagógico que respeite as especificidades e heterogeneidade do público trabalhador do noturno, enfatize e atribua a devida valorização do trabalho empenhado pelos docentes comprometidos com a educação.

\subsubsection{Pesquisa e extensão}

A maior parte dos entrevistados não soube avaliar em que medida sua participação em pesquisa e extensão pode ser considerada um dos elementos para a formação na universidade. Os entrevistados explicam que não participam, porque a pesquisa e extensão acontecem durante o dia, período em que não estão na universidade e estão desempenhando atividades trabalhistas.

Não participo, não [...], por causa do tempo mesmo, porque exige uma dedicação, assim, meio que exclusiva, eu considero. E eu não estou ainda disposta, eu preciso trabalhar. [...] geralmente, a faculdade oferece a maioria das coisas, quando não é pela manhã é o dia todo, é manhã e tarde, então eu tô no trabalho, não posso participar (Júlia, estudante de Pedagogia).

O diurno tem o espaço da manhã e da tarde pra fazer extensão, essas coisas a gente não tem oportunidade [...]. A gente fica muito limitado a participar de eventos que acontecem aqui na própria universidade, porque não é pensado pra o noturno, pra o curso noturno. É pensado pra o diurno. Trabalhos de extensão, pesquisas, congressos, seminários, simpósios... a gente fica muito limitado mesmo (José Ricardo, estudante de Direito).

Grupo de pesquisa, eu tentei frequentar um, só que o horário era à tarde, ficou muito puxado devido ao trabalho de manhã [...]. Eu não sei o que dizer da extensão, nunca tive experiência com extensão até agora (Rita, estudante de Língua Estrangeira Inglês/Espanhol)

As falas dos estudantes sobre a não participação na pesquisa e na extensão devido ao fato de elas ocorrerem em horários em que não estão matriculados e/ou frequentando a universidade contraria o que rege o Estatuto e Regimento Geral da UFBA. Percebe-se que a tripla missão de produção formativa, intelectual ou acadêmica e produção política, estabelecida no novo marco normativo da instituição, não acontece para todos. Seu papel histórico fica comprometido quando se refere ao seguimento de estudantes trabalhadores do noturno. Ora, se a universidade aderiu ao Reuni para garantir a democratização de acesso, especialmente no período noturno, expandindo seu número de matrículas, deveria 
ter procurado conhecer o perfil dos estudantes que iria receber e programar-se em seus projetos pedagógicos para atendê-los igualmente, oferecendo-lhes sua tripla função através do ensino, da pesquisa e da extensão.

Há histórias impressionantes de estudantes que conseguiram ingressar num grupo de pesquisa e que tentaram driblar as adversidades, como sua escassez para o curso noturno e a própria condição de trabalhador diurno.

Apenas seis estudantes declararam não ter interesse ou nunca ter tentado se inscrever para as bolsas. A maior parte justifica que o período em que o bolsista desenvolve a pesquisa é durante o dia, quando estão trabalhando e não estão na universidade para tal atividade.

Os próprios estudantes, durante a entrevista, fizeram uma reflexão crítica a respeito da ausência ou da escassez de pesquisa e extensão para os cursos noturnos. Segundo eles, a universidade, que se caracteriza como uma instituição de ensino, pesquisa e extensão, se mostra incompleta para os cursos noturnos, apresentando-se somente como instituição de ensino. De acordo com o depoimento de um entrevistado, os estudantes do noturno não usufruem da indissociabilidade do conhecido "tripé" ensino, pesquisa e extensão, porque lhes restou apenas o ensino:

Então, foi pensado o curso noturno de uma maneira elitista, uma maneira rápida, apenas nessa reformulação de novos projetos da educação superior, de modernização [...], foi pensado apenas pra cumprir tabela, mas não pensado nas consequências que poderiam advir com isso: limitação da pesquisa do aluno noturno. O aluno noturno não tem como fazer pesquisa, porque normalmente o que é que o aluno noturno faz: ele trabalha, trabalha oito horas. Então, é muito complicado pra ele. Ele não tem como fazer pesquisa, a não ser que ele renuncie o trabalho, largue o trabalho. E, muitas vezes, quem trabalha é pai de família, chefe de família (Guilherme, estudante de Direito).

A fala do estudante ratifica as considerações feitas sobre a universidade de ensino deixada para os estudantes do noturno e está alinhada com a ideia discutida pelo Forproex (2006) sobre a indissociabilidade ensino, pesquisa e extensão ser um eixo de formação do estudante para que o curso universitário vá além da transmissão do conhecimento e se transforme em espaço de construção deste. 
Os argumentos do entrevistado, ao serem analisados a partir dos conceitos da etnometodologia, principalmente da ideia de indexicalidade e de noção de membro, retoma a discussão feita por Bourdieu e Champagne (2008) sobre os excluídos do interior. Sua fala denuncia a inclusão na universidade, do ponto de vista da democratização de acesso, e a exclusão que ocorre no interior da instituição, no que se refere aos impeditivos para participar da pesquisa e da extensão.

Percebe-se, então, que a formação universitária que leva em consideração ensino, pesquisa e extensão se apresenta muito confusa para os estudantes do noturno. Se há evidências de que há mais incentivo e supervalorização da pesquisa na academia (PAIVANDI, 2013; SOARES, 2009), desde a formação stricto sensu dos professores, poderia se pensar que a práxis em pesquisa, com os estudantes, deveria acontecer com mais frequência através de projetos e editais para o noturno.

Os relatos sobre a ausência de pesquisa e extensão nos cursos noturnos indicam contradição diante da supervalorização da pesquisa. Os mesmos professores que recebem incentivos para serem pesquisadores e até gozam desse reconhecimento praticam apenas o ensino no período noturno, sendo relegada a pesquisa. Esse não é um problema isolado do professor, nem é apenas sua a responsabilidade. A contradição tem suas bases na política e gestão universitária que ignora o tipo de formação oferecida a cada turno e que ainda não absorveu por completo a ideia de democratização do Ensino Superior para as massas, conforme estabelecido nos documentos oficiais.

\subsection{O funcionamento dos espaços da universidade no período noturno}

Os entrevistados avaliam muito negativamente o funcionamento dos espaços físicos e instalações da UFBA que favoreçam a execução de atividades complementares da formação acadêmica no período noturno. Os principais elementos relacionados ao funcionamento noturno apontados são: as secretarias de curso, colegiados e demais secretarias da UFBA, as unidades de ensino, as bibliotecas, os eventos acadêmicos como seminários e simpósios em auditórios ou em outros espaços, as copiadoras de textos, os restaurantes e lanchonetes, o sistema de transporte Buzufba, assim como a segurança e a iluminação.

Quase todos os estudantes informaram que no período noturno as secretarias e colegiados de seus cursos funcionam em horário reduzido. Vale ressaltar que 0 horário de funcionamento das aulas do turno noturno é das $18 \mathrm{~h} 30 \mathrm{~min}$ às $22 \mathrm{~h} 30 \mathrm{~min}$. Entretanto, os horários das secretarias são diversificados para cada curso e não 
padronizados para todos os campi ou unidades de ensino. De acordo com os entrevistados, há unidade de ensino que funciona até as $18 \mathrm{~h}$, outras até as $19 \mathrm{~h}$, outras até as $18 \mathrm{~h} 30 \mathrm{~min}$ e outras até $21 \mathrm{~h}$. A Secretaria Geral de Cursos (SGC) também fecha às $20 \mathrm{~h}$, prejudicando a solicitação de procedimentos administrativos referentes ao curso.

\begin{abstract}
Assim, a escola é abandonada, os alunos não têm informação das coisas que acontecem, as programações, normalmente, são durante o dia e a gente fica sem assistência alguma, não tem colegiado aqui presente à noite. Direção... é muito difícil a gente ter o contato com essas pessoas à noite, porque a gente não sabe quem são. À tarde, não sabe a quem procurar. Então, de certa forma, a gente tá totalmente abandonados aqui no noturno [...]. Não existe atendimento no noturno, é tudo muito precário, não existe diretoria [...]. Normalmente você encontra a diretora até as $17 \mathrm{~h}$, a partir daí a escola fica vazia, com pouco segurança, com uma recepção que não sabe dar informação alguma [...]. Olha, o que eu poderia acrescentar, assim, é solicitar mesmo uma presença maior da diretoria da escola, ter mais contato com os alunos do noturno, porque, de certa forma, a gente não tá sendo assistido na maioria das coisas (Ronaldo, estudante de Dança).
\end{abstract}

Outros estudantes trazem como possível solução para o problema do funcionamento de secretarias e colegiados no período noturno a jornada de turnos contínuos, pauta de reivindicação da categoria de trabalhadores técnico-administrativos da universidade. No final de 2013, a Reitoria da UFBA regulamentou o processo de implementação e avaliação da flexibilização para ajuste de jornada de trabalho desses servidores, para complementar o funcionamento dos três turnos: matutino, vespertino e noturno. A estudante de Língua Estrangeira Inglês/Espanhol comenta essa situação:

Se você não correr, você não pega os lugares abertos. Xerox fecha mais cedo, o colegiado fecha [...] antes do horário do noturno acabar e algumas pessoas não têm como chegar mais cedo pra poder resolver alguns problemas que poderiam ser resolvidos rápidos e que causam muita dor de cabeça e transtornos. Então, acho que esse horário poderia ser estendido, contratando mais pessoas, criando um tipo de tabela de horários e tal (Rita, estudante de Língua Estrangeira Inglês/Espanhol). 
A fala da estudante indica o quanto é afetada pelo funcionamento inadequado da instituição no período noturno, corroborando para o entendimento de relatos anteriores sobre obstáculos enfrentados pelos colegas. Além disso, dá dicas de gestão institucional para possíveis soluções no funcionamento noturno das secretarias e colegiados.

Os trabalhadores-estudantes reclamam das normas da matrícula, porque não são democráticas, atendem a uns e prejudicam a outros. Sugerem que a matrícula do noturno tenha início e fim, de acordo com o horário das aulas - das 18h30min às $22 \mathrm{~h} 30 \mathrm{~min}, \mathrm{e}$ assim atenda a todos igualmente:

[...] a gente tem que estudar à noite e fazer matrícula de dia, acho que não convém. Se a gente estuda à noite, não é porque a gente quer estudar à noite. Mas se estuda à noite, porque muita gente ali trabalha, alguns podem até estudar à noite, porque querem ter o tempo livre durante o dia, mas a maioria está com o dia ocupado, trabalhando. Então, é ter que solicitar folga, ter que faltar ao trabalho pra tá ali fazendo matrícula [...] (Rosana, estudante de Direito).

Mediante todas as falas, percebe-se que, de fato, há incoerência entre os horários de funcionamento das secretarias e colegiados e das aulas. Como explicou a estudante de Direito, este problema se acentua no período de matrícula, mas permanece durante todo o ano letivo, obrigando, muitas vezes, o estudante ir à secretaria resolver um problema, sob pena de prejudicar seu direito de assistir a aula. Se estes espaços, que são vitais para o funcionamento e a organização dos cursos e das unidades de ensino, funcionassem de $18 \mathrm{~h} 30 \mathrm{~min}$ às $22 \mathrm{~h} 30 \mathrm{~min}$, seguindo os horários dos cursos noturnos, o estudante poderia escolher procurar as secretarias e colegiados em seus horários de intervalo, por exemplo, e assim teriam assegurados o acesso aos serviços administrativos sem maiores prejuízos.

Há unidade de ensino que não funciona no período noturno e os estudantes são remanejados para outras unidades de ensino. Esse é o caso da Faculdade de Filosofia e Ciências Humanas, do campus de São Lázaro, que oferece o curso noturno de História em pavilhões de aula do campus de Ondina, como esclarece a estudante abaixo:

Tem a questão do nosso curso de História, da nossa coordenação [que], geralmente, a coordenadora só fica disponível até as seis horas [da noite] e aí, pra poder falar com ela alguma coisa [...], você precisa ir na coordenadoria que é lá em São Lázaro e pra quem, 
no meu caso, que trabalho, não tenho disponibilidade de vir até a UFBA durante o dia... São Lázaro não funciona à noite, eu vou ter que entrar em contato com a coordenadora pra pedir um favor pra que ela esteja disponível pra conversar comigo durante a noite e aí ficar dependendo dela (Joana, estudante de História).

A fala da estudante sobre pedir favor à coordenadora de curso indica que, em determinados setores da instituição, a universidade está condicionando estudantes, professores e demais funcionários às relações consuetudinárias e não institucionais. Assim, pode-se inferir que esse tipo de relação permite brechas para acordos tácitos enquanto que a universidade deveria resolver suas precariedades, tais como a regulamentação da extensão de horários dos seus profissionais ou contratação de novos funcionários, bem como fazer com que houvesse o funcionamento pleno de todas as unidades de ensino e demais espaços físicos de maneira que a igualdade de funcionamento para os cursos noturnos fosse respeitada.

Os entrevistados referem ainda que as bibliotecas funcionam em horários reduzidos e diversificados e a afirmação de que fecham antes de terminar as aulas foi unânime entre eles (das $17 \mathrm{~h}$ às $22 \mathrm{~h}$ ):

No início do curso noturno não tinha atendimento; aí depois de uns três anos pra cá a coisa vem melhorando. Já teve a biblioteca que funciona até 8 horas [da noite], o RU até 8 horas, o Buzufba funciona até umas 10 horas, né, e o SGC também é até as 8 horas, mas no geral, não estende pra abranger todo o tempo que o aluno noturno tá na casa. Acho que teria que estender isso aí pra todo o horário que o aluno esteja na casa. A biblioteca tem que tá disponível, pelo menos até umas 11 horas da noite, pelo menos a biblioteca, né, que, às vezes, o aluno não tem condição de tá no primeiro horário na biblioteca, mas tem o segundo. Às vezes, a gente não tem acesso, porque a biblioteca já está fechada. E é todo mundo que tem condições de comprar livros, material didático? Acho que o funcionamento da universidade tem que ser em tempo integral, da hora da entrada do aluno até a saída (Francisco, estudante de Matemática).

As queixas sobre os horários de funcionamento das bibliotecas são de grande relevância, porque impactam diretamente no desempenho do estudante, no que diz respeito a prejudicar-se por não ter conseguido tomar livros emprestados ou por não assistir às aulas dos professores para ir pegar livros na biblioteca. 
Embora os eventos acadêmicos estejam mais relacionados às atividades de pesquisa e extensão, os entrevistados também os citaram quando questionados sobre sua percepção a respeito do funcionamento dos espaços físicos e instalações da UFBA. Muitos associaram os horários em que acontecem tais atividades com os horários de funcionamento dos espaços físicos e afirmaram que no noturno há pouca oferta de eventos acadêmicos ou que não acontecem, sinalizando para desigualdades existentes entre os turnos, como se pode constatar nos seus relatos:

Tem uma questão complicada pro curso noturno, principalmente, palestra, seminários, essas coisas... e grupo de pesquisa também, é só mesmo pra o diurno, porque a gente da noite pra participar disso tem que pegar disciplina de dia ou tem que se disponibilizar pra tá aqui de dia. Então, palestra, seminário, a maioria dessas coisas, a gente tem que se dispor a tá aqui de dia. Se for pra fazermos a graduação toda, simplesmente focado nesse horário do noturno tem uma defasagem muito grande em relação ao pessoal do diurno. A gente fica muito atrás, questão de... essa carga horária mesmo, temos que ter 200 horas de carga horária complementar. A gente só complementa essa carga horária no diurno. [...] não conseguimos eventos à noite pra tá indo e quando conseguimos, conciliar a aula com o evento não dá. Ou a gente assiste a aula ou vai pro evento. Então, é complicado isso aí (Valentina, estudante de Letras Vernáculas).

Os relatos estudantis trazem uma preocupação quanto às atividades extracurriculares que são mais ofertadas no diurno e raramente ofertadas no noturno. Elas servem para repensar o artigo 47 da LDB de 1996 (BRASIL, 1996) sobre o diurno como parâmetro de qualidade do curso noturno. $\mathrm{O}$ estudante-trabalhador e o trabalhador-estudante não podem ficar condicionados a uma situação como a relatada, em que para realizarem atividades extracurriculares devam frequentar a universidade em horários que lhes parecem impossíveis. É de responsabilidade da universidade repensar urgentemente esse parâmetro e criar condições propícias para o melhor aproveitamento do estudante, de maneira a estagnar os prejuízos existentes.

É interessante analisar como os estudantes constroem seus relatos, pois ao mesmo tempo em que apresentam os problemas que os circundam quanto a sua participação nos espaços universitários, também dão soluções para eles. Partindo da etnometodologia, para que se compreenda esse fato, Coulon (1995) explica que a fala é um indicador de um contexto, que compreendê-la é compreender o lugar do qual se fala. Nesse sentido, salienta-se a grandeza das falas estudantis, 
porque elas surgem para mostrar o que os indivíduos que estão fora de seu contexto não conseguem perceber.

\section{Considerações finais}

A percepção dos estudantes apresentada nessa pesquisa se faz relevante por expor a face do Ensino Superior noturno que, comumente, não é vista nas pesquisas acadêmicas. É a face vista por quem o vivencia e não apenas de quem a observa. As contribuições decorrentes desse estudo permitiram ampliar o olhar sobre como vem sendo tratado o Ensino Superior noturno na UFBA e dão pistas de alternativas de mudança que esta instituição poderia considerar em prol dos estudantes desse turno.

O recente processo de expansão dos cursos noturnos é um fato importante e necessário diante da carência desse segmento de ensino na universidade pública. Porém, critica-se a ampliação tardia dos cursos noturnos pelo fato de a UFBA, instituição mais antiga do estado, que goza de certos privilégios e respeitabilidade, pioneira em tantas questões, só se preocupar em cumprir esse papel social com estudantes trabalhadores tão recentemente, depois que as demais instituições de Ensino Superior da Bahia já lhe davam cobertura há bastante tempo.

A conclusão que se chegou com esta pesquisa é que os estudantes percebem o Ensino Superior noturno da UFBA como algo fragmentado, incompleto para estudantes-trabalhadores e trabalhadores-estudantes. Eles entendem que, embora a universidade ofereça ensino, pesquisa e extensão, essa tripla função não foi pensada para eles, sobrando-lhes apenas o ensino. Além disso, problemas estruturais de funcionamento noturno da instituição comprometem o acesso a todos os serviços internos que a universidade oferece. Ressalta-se que a universidade deu um grande passo no que se refere à democratização de acesso ao Ensino Superior, por meio dos cursos noturnos, mas falta-lhe ainda uma longa caminhada para atender aos estudantes com igualdade social, respeitando suas especificidades pedagógicas e proporcionando-lhes melhor usufruto dos serviços administrativos, de pesquisa e de extensão. Destaca-se que os estudantes-trabalhadores e os trabalhadores-estudantes, que compõem a maior parte do público discente noturno, carecem de melhor atendimento. Inclusive tiveram poucos registros de sua presença ao longo da história da Universidade Federal da Bahia.

Apesar das questões discutidas e das sugestões trazidas serem direcionadas à UFBA, porque foi a instituição tomada como campo da pesquisa, há de se reconhecer que muitos dos problemas apontados dizem respeito a uma macropolítica do estado brasileiro. As políticas nacionais de educação têm o dever de rever, 
por exemplo, a assistência estudantil, pois o público que destas necessita na universidade é, também, o mesmo que precisa de assistência das políticas socais governamentais. O perfil dos entrevistados não difere tanto do perfil da população que é explorada no país.

As normas dos editais de programas de iniciação científica, quanto à proibição do vínculo empregatício nos pré-requisitos de seleção dos estudantes, são nacionais. A formação de professores universitários é um problema que o Ministério da Educação, junto à Coordenação de Aperfeiçoamento de Pessoal de Nível Superior (Capes) precisam discutir. E a política nacional de implantação do Ensino Superior noturno, que vise considerar a permanência bem-sucedida do estudante, deve transversalizar todas as questões estruturais da educação brasileira, dialogando diretamente com a educação básica (base dos estudantes que chegam ao Ensino Superior) e com a ideia de uma educação pública, de qualidade e para todos. Não se pode colocar a ingenuidade à frente dessas questões e esperar que apenas o Programa Reuni dê conta da estruturação e organização dos cursos noturnos. É preciso um esforço maior para com as demais políticas educacionais.

Para atender melhor e dar visibilidade aos estudantes que trabalham, é necessário que a universidade prossiga além da democratização de acesso, muito usada nos discursos. Deve também fazer a democratização intramuros: dentro das unidades de ensino, dentro dos cursos, no usufruto dos serviços internos, sejam eles administrativos, de pesquisa ou de extensão, para que, de fato, os estudantes, cujo capital econômico é reduzido, possam permanecer e concluir seus cursos com menos desigualdades.

Portanto, as questões imbricadas nessa pesquisa tomam como ponto de partida o Ensino Superior noturno da UFBA, mas podem servir de instrumento de reflexão sobre os cursos noturnos numa conjuntura nacional de educação. Em suma, todas as percepções, dos pesquisados e da pesquisadora, formam um conjunto de dados ou informações que poderão fornecer subsídios aos interessados, no sentido de promover mais que a democratização de acesso, ajudando a repensar a democratização da permanência qualificada e da conclusão bem-sucedida do curso superior noturno. 


\title{
The evening education in the Universidade Federal da Bahia: students' perception
}

\begin{abstract}
From the Program of Support to Restructuring and Expansion Plans of Federal Universities (REUNI), 2007, UFBA expands from 2 to 33 evening courses, increasing to 9000 students this turn, in 2013. The present study aims to know the students' perception about evening higher education. Among the bases of studies that support this research are Arroyo, Furlani e Terribili Filho, who discuss, respectively: evening courses for workers from popular classes; challenges and facing of pedagogical proposes; teaching methods; and public policies. The research makes use of the qualitative methodology, from a ethnomethodological approach, and is based on techniques of questionnaire application, individual interviews and focal groups. The survey results showed that students perceive UFBA's evening higher education as fragmented and incomplete, where, at the expense of research and extension, education presents itself as the only role of the university in this turn. In addition, the statements verify structural problems in the night operation of the institution that compromise the access to the internal services that it offers. From these results we propose some alternatives for changes that may contribute to the management and planning of the university through democratizing access.
\end{abstract}

Keywords: University. Evening higher education. Students. Public policy.

\section{Los cursos nocturnos de la Universidad Federal de Bahía: percepciones de los estudiantes}

\section{Resumen}

Desde del Programa de Apoyo a los Planes de Reestructuración y Expansión de las Universidades Federales (REUNI), de 2007, la UFBA amplió de 2 a 33 cursos nocturnos, llegando a tener más de 9000 estudiantes de este turno en 2013. Este estudio tiene como objetivo conocer la percepción de los estudiantes acerca de la educación superior nocturna. Entre las bases de los estudios que apoyan esta investigación están Arroyo, Furlani y Terribilli Filho, que discuten, respectivamente: cursos nocturnos para los trabajadores de las clases más bajas; dificultades y propuestas de afrontamiento; propuestas pedagógicas; métodos de enseñanza; y politicas. Para ello, la investigación utiliza la metodología cualitativa, de enfoque etnometodológico, y se basa en la técnica de aplicación de cuestionarios, entrevistas individuales y grupos focales. Los resultados del estudio mostraron que los estudiantes perciben la educación superior nocturna de la UFBA como fragmentada e incompleta que, en detrimento de la investigación y la extensión, la enseñanza se presenta en este turno como la única función de la universidad. Además, los testimonios constatan problemas estructurales en el funcionamiento nocturno de la institución que comprometen el acceso a los servicios internos que ella ofrece. Las cuestiones imbricadas en esta investigación pueden servir como instrumento de reflexión sobre los cursos nocturnos en un ambiente nacional de educación, a través de democratización del acceso.

Palabras clave: Universidad. Educación superior nocturna. Estudiantes. Políticas públicas. 


\section{Referências}

ALMEIDA FILHO, N. et al. Memorial da Universidade Nova: UFBA 2002-2010. Salvador: EDUFBA, 2010.

ARROYO, M. G. A. O direito do trabalhador à educação. In: GOMEZ, C. M. et al. Trabalho e conhecimento: dilemas na educação do trabalhador. 5. ed. São Paulo: Cortez, 2004. p.75-92

. Universidade, o trabalho e o curso noturno. Estudos e Debates, n. 17, p. $91-4,1990$.

BARREIRO, I. M. F.; TERRIBILI FILHO, A. Educação superior no período noturno no Brasil: políticas, intenções e omissões. Ensaio: Avaliação e Políticas Públicas em Educação, v. 15, n. 54, p. 81-102, jan./mar. 2007. http://doi.org/10.1590/S0104-40362007000100006

BAUER, M. W.; AARTS, B. A construção do corpus: um princípio para a coleta de dados qualitativos. In: BAUER, M. W.; GASKELL, G. Pesquisa qualitativa com texto, imagem e som: um manual prático. Petrópolis: Vozes, 2002. p. 39-63.

BOURDIEU, P.; CHAMPAGNE, P. Os excluídos do interior. In: BOURDIEU, P. et al. A miséria do mundo. 7. ed. Petrópolis: Vozes, 2008. p. 481-6.

BRASIL. Lei no 9.394, de 20 de dezembro de 1996. Estabelece as diretrizes e bases da Educação Nacional. Diário Oficial da União, 23 dez. 1996.

. Ministério da Educação. REUNI - Reestruturação e Expansão das Universidades Federais: diretrizes gerais (Portaria $\mathrm{n}^{\circ}$ 552, SESu/MEC, de 25 de junho de 2007, em complemento ao art. $1^{\circ} \S 2^{\circ}$ do Decreto Presidencial no 6.096, de 24 de abril de2007). Brasília, DF, 2007.

CARDOSO, R.; SAMPAIO, H. Estudantes universitários e o trabalho. Revista Brasileira de Ciências Sociais, v. 9, n. 26, p. 30-50, out. 1994.

COULON, A. A. Etnometodologia. Petrópolis: Vozes, 1995.

FÓRUM DE PRÓ-REITORES DE EXTENSÃO DAS UNIVERSIDADES PÚBLICAS BRASILEIRAS - FORPROEX. Indissociabilidade

ensino-pesquisa-extensão e a flexibilização curricular: uma visão da extensão. Porto Alegre: UFRGS/Brasília, DF: MEC/SESu, 2006. Disponível em: <http:// www.uemg.br/downloads/indissociabilidade_ensino_pesquisa_extensao.pdf $>$. Acesso em: 16 fev. 2016. 
FRASER, M. T. D.; GONDIM, S. M. G. Da fala do outro ao texto negociado: discussões sobre a entrevista na pesquisa qualitativa. Paidéia (Ribeirão Preto), v. 14, n. 28, p. 139-52, 2004. http://doi.org/10.1590/S0103-863X2004000200004

FREIRE, P. Extensão ou comunicação? 8. ed. Rio de Janeiro: Paz e Terra, 1983.

. Pedagogia da autonomia: saberes necessários à prática educativa. 36. ed. São Paulo: Paz e Terra, 2007. . Pedagogia do oprimido. 47. ed. Rio de Janeiro: Paz e Terra, 2008.

FURLANI, L. M. T. A claridade da noite: os alunos do Ensino Superior noturno. 2. ed. São Paulo: Cortez, 2001.

GARFINKEL, H. O que é etnometodologia? Revista Teoria e Cultura, v. 4, n. 1/2, p. 113-34, jan./dez. 2009.

GASKELL, G. Entrevistas individuais e grupais. In: BAUER, M. W.;

GASKELL, G. Pesquisa qualitativa com texto, imagem e som: um manual prático. Petrópolis: Vozes, 2002. p. 64-89.

GIL, R. Análise de discurso. In: BAUER, M. W.; GASKELL, G. Pesquisa qualitativa com texto, imagem e som: um manual prático. Petrópolis: Vozes, 2002. p. 244-70.

GONDIM, S. M. Grupos focais como técnica de investigação qualitativa: desafios metodológicos. Paidéia, Ribeirão Preto, v. 12, n. 24, p. 149-161, 2003. http://doi.org/10.1590/S0103-863X2002000300004

INSTITUTO BRASILEIRO DE GEOGRAFIA E ESTATÍSTICA - IBGE. Censo demográfico 2010: trabalho e rendimento: resultados da amostra. Rio de Janeiro, 2010.

LIBÂNEO, J. C. Conteúdos, formação de competências cognitivas e ensino com pesquisa: unindo ensino e modos de investigação. São Paulo: Pós-Reitoria de Graduação, 2009. (Cadernos de pedagogia universitária, v. 11).

LUCKESI, C. et al. Fazer universidade: uma proposta metodológica. 6. ed. São Paulo: Cortez, 1991.

MARX, K. O capital: crítica da economia política. São Paulo: Nova Cultural, 1996. t. 1. (Os economistas, 1). 
NERY, M. B. M. et al. Um novo universitário: estudantes de origem popular na UFBA. In: SAMPAIO, S. M. R. (Org.). Observatório da vida estudantil: primeiros estudos. Salvador: EDUFBA, 2011. p. 93-113.

NOSELLA, P. Trabalho e educação. In: GOMEZ, C. M. et al. Trabalho e conhecimento: dilemas na educação do trabalhador. 5. ed. São Paulo: Cortez, 2004. p. 27-41.

PAIVANDI, S. Avaliação do ensino superior pelo estudante, a pedagogia universitária e o ofício de professor. In: SANTOS, G. G.; SAMPAIO, S. M. R. (Org.). Observatório da vida estudantil: universidade, responsabilidade social e juventude. Salvador: EDUFBA, 2013. p. 319-52.

SANTANA, C. B. A caminho da democratização da UFBA: o novo aluno dos cursos noturnos. 2013. 243 f. Dissertação (Mestrado em Estudos Interdisciplinares sobre a Universidade) - Instituto de Humanidades, Artes e Ciências, Universidade Federal da Bahia, Salvador, 2013.

SOARES, S. R. Pedagogia universitária: campo de prática, formação e pesquisa na contemporaneidade. In: NASCIMENTO, A. D.; HETKOWSKI, T. M. (Org.). Educação e contemporaneidade: pesquisas científicas e tecnológicas. Salvador: EDUFBA, 2009.

TERRIBILI FILHO, A. Educação superior no período noturno: impacto do entorno educacional no cotidiano do estudante. 2007. 186 f. Tese (Doutorado em Educação) - Faculdade de Filosofia e Ciências, Universidade Estadual Paulista, Marília, 2007.

TERRIBILI FILHO, A.; NERY, A. C. B. Ensino superior noturno no Brasil: história, atores e políticas. Revista Brasileira de Política e Administração da Educação, v. 25, n. 1, p. 61-81, jan./abr. 2009. http://doi.org/10.21573/vol25n12009.19327

TERRIBILI FILHO, A.; QUAGLIO, P. O cenário urbano para o estudante do Ensino Superior noturno na cidade de São Paulo: triste realidade ou palco de heróis? Millenium, v. 9, n. 31, p. 74-87, mai. 2005.

UNIVERSIDADE FEDERAL DA BAHIA - UFBA. Estatuto e regimento geral. Salvador, 2010. Disponível em: $<$ https://www.ufba.br/ sites/www.ufba.br/files/estatuto_regimento/index.html>. Acesso em: 20 nov. 2014. 
UNIVERSIDADE FEDERAL DA BAHIA - UFBA. Pró-Reitoria de Ações Afirmativas e Assistência Estudantil - Coordenação dos Programas de Assistência ao Estudante. Edital $n^{\circ}$ 02/2014: inscrição para benefícios e programas da PROAE - 2014.2. Salvador, 2014a.

. Pró-Reitoria de Planejamento e Orçamento - PROPLAN. Perfil sócio-econômico dos candidatos inscritos e classificados no concurso vestibular da UFBA 2001-2004. Salvador, 2005.

. Pró-Reitoria de Planejamento e Orçamento - PROPLAN. Perfil

socioeconômico dos candidatos inscritos e classificados no concurso vestibular da UFBA 2005-2008. Salvador, 2008.

. Pró-Reitoria de Planejamento e Orçamento - PROPLAN. Relatório de Gestão UFBA 2012: simplificado. Salvador, 2013.

. Pró-Reitoria de Planejamento e Orçamento - PROPLAN. Relatório de Gestão UFBA 2013: complementar. Salvador, $2014 \mathrm{~b}$.

VARGAS, H. M.; PAULA, M. F. C. A inclusão do estudante-trabalhador e do trabalhador-estudante na educação superior: desafio público a ser enfrentado. Avaliação (Campinas), v. 18, n. 2, p. 459-85, jul. 2013. http://doi.org/10.1590/S1414-40772013000200012

\section{Informações das autoras}

Jucilene Dias Maranhão: Mestre em Estudos Interdisciplinares sobre a Universidade pela Universidade Federal da Bahia - UFBA. Foi bolsista da Capes (Capacitação de Aperfeiçoamento de Pessoal de Nível Superior). Pedagoga e Bacharel em Humanidades. Contato: jucimaranhao@yahoo.com.br

Renata Meira Veras: Doutora em Psicologia Social pela Universidade Federal do Rio Grande do Norte - UFRN. Professora Adjunta do Programa de Pós-Graduação em Estudos Interdisciplinares sobre a Universidade da Universidade Federal da Bahia - UFBA. Psicóloga e Fisioterapeuta. Contato: renata.veras@ufba.br 